\section{Spectral Quality of Light Can Affect Energy Consumption and Energy-use Efficiency of Electrical Lighting in Indoor Lettuce Farming}

\author{
Yuyao Kong, Ajay Nemali, Cary Mitchell, and Krishna Nemali ${ }^{1}$ \\ Department of Horticulture and Landscape Architecture, Purdue University, \\ West Lafayette, IN 47907
}

Additional index words. broad spectrum, hydroponics, Lactuca sativa, phosphor-converted LED, purple light, vertical farm, white light

\begin{abstract}
High energy-use cost for electric lighting is one of the major issues challenging sustainability of the indoor lettuce-farming industry. Thus, maximizing electrical energy-use efficiency (EUE, $\mathrm{g} \cdot \mathrm{KWh}^{-1}$ ), defined as the ratio of dry matter production (g) to electrical energy consumption $\left(\mathrm{EEC}, \mathrm{KWh}^{-1}\right)$, is crucial during indoor production. Light-emitting diodes (LEDs) are energy efficient and highly suitable for indoor farms. Research on optimal spectral quality of LEDs for lettuce growth is extensive; however, there is limited research examining LED spectral quality effects on EEC and EUE. Photon efficiency, defined as the ratio of light output to electrical energy input (PE, $\left.\mu \mathrm{mol} \cdot \mathrm{J}^{-1}\right)$, generally is used for selection of LED fixtures. Because PE does not account for differences in emitted light spectrum, it is not clear whether light-fixture selection based on PE can maximize EUE in lettuce production. This study comprised two experiments. In Expt. 1, we used four "phosphor-converted" commercial LEDs with different light intensities and spectra to model the effect of light spectral quality on lettuce shoot dry weight (SDW), EEC, and EUE. We also evaluated relations between EUE vs. PE and EUE vs. $P_{R}$ (PE based on red light) for indoor lettuce production. Results indicated that light spectral quality affected SDW, EEC, and EUE in lettuce production. Fitted models indicated that EEC increased linearly with increasing percentage of red-light output and was unaffected by other spectral colors or ratios. However, EUE increased in a curvilinear fashion with an increasing ratio of red to blue (R:B) light and reached a maximum at a ratio of 4.47. Similar to EUE, SDW also responded in a curvilinear fashion to R:B. Results also indicated that EUE correlated poorly with $\mathrm{PE}$ but linearly to $\mathrm{PE}_{\mathrm{R}}$. In Expt. 2, we grew three lettuce varieties under two commercial $L E D$ fixtures. They had similar levels of $P E$ but different percentages of red, $R: B$, and $P E_{R}$ values. Regardless of the variety, fixtures with greater percentages of red, $R: B$, and $P E_{R}$ significantly increased EUE. We conclude that red-light quality is an important determinant of EUE and growers should select fixtures based on $R: B$ and high $\mathrm{PE}_{\mathbf{R}}$ in indoor lettuce farming.
\end{abstract}

Indoor farming (including vertical and horizontal methods) involves growing food crops under sole-source electric lighting inside buildings, including warehouses. This system is gaining importance globally, especially near urban areas (Rabara et al., 2017). Leafy greens, such as lettuce, are among the group of popular crops for indoor farming (Kozai, 2013). Crops are produced using electric lighting for an average of 16 $\mathrm{h} \cdot \mathrm{d}^{-1}$ (Agrilyst, 2017) in indoor farms. Thus, electrical energy-use costs can be quite high in indoor farming (Barbosa et al., 2015; Shimizu et al., 2011). Due to their relatively low thermal emissions (Nelson and Bugbee, 2014; Poulet et al., 2014), LEDs can be

Received for publication 21 Dec. 2018. Accepted for publication 27 Feb. 2019.

We thank Ranjeeta Adhikari and Alexander Miller for helping with harvest.

${ }^{1}$ Corresponding author. E-mail: knemali@purdue. edu. placed close to a canopy to reduce photon losses (Bourget, 2008; Poulet et al., 2014), and subsequently are desirable for indoor farming. Despite using LEDs, estimates indicate that energy costs for electric lighting can be as high as $25 \%$ to $30 \%$ of operational costs in indoor farming (Agrilyst, 2017; Voss, 2011), which significantly reduces profits. At present, this is one of the major issues challenging profitability and sustainability of the indoor farming industry.

Broad-spectrum LED lights generally are preferred in horticulture production as they enable better visual assessments of plants, and crop growth under these lights is comparable or better than that under monochromatic LED lights (Mickens et al., 2018; Park and Runkle, 2018). Broad-spectrum light usually is produced by a process called "phosphor conversion" (pc) in newer commercial LED fixtures. This involves coating blue LEDs with "phosphor" (a synthetic material with luminescence property), which absorbs blue light and re-emits light of lower energy (phenomenon known as "down conversion") wavebands (Huang and Yang, 2013; Pattison et al., 2018; Ryu and Ryu, 2015; Yam and Hassan, 2005). This method is more economical as opposed to combining red, green, and blue monochromatic LEDs to produce broad-spectrum light, mainly due to the low quantum efficiency of monochromatic green LEDs (Pust et al., 2015). By fine-tuning the phosphor chemical composition and concentration, different percentages of green and red light can be produced from blue light.

When generating lower energy light from greater energy blue photons in pcLEDs, some electrical energy is lost as thermal dissipation inside the phosphor (Huang and Yang, 2013), which increases phosphor temperature. Greater phosphor temperature lowers phosphor efficiency (Ryu and Ryu, 2015). This suggests that EUE can be lower when a greater proportion of red light is emitted by phosphor due to a larger "down conversion" involved (blue vs. red) and increased wastage of electrical energy in the form of heat as a result. In contrast, a greater proportion of red light in the incident light may be preferred for lettuce production as it increases leaf expansion and shoot growth (Kang et al., 2016; Lee and Kim, 2013; Wang et al., 2016; Zhang X. et al., 2018). Thus, the spectral quality of LEDs can potentially influence EUE by affecting both SDW and EEC in opposite ways. However, studies simultaneously examining the effects of the spectral quality of LEDs on lettuce SDW, EEC, and EUE are limited in terms of the net effects on productivity.

Manufacturers of LED fixtures commonly use PE to characterize light fixtures (Both et al., 2017; Nelson and Bugbee, 2014; Park and Runkle, 2018). Greater PE values are associated with lower energy costs of producing artificial light (Kubota et al., 2016) and can thereby increase EUE (Park and Runkle, 2018). This measurement is specific to a given fixture, and as such it is broadly useful for light-fixture selection for different species and purposes. An issue with using PE for maximizing EUE is that it is solely based on light intensity, or the number of photons generated by the fixture for a given input of electrical energy, but does not indicate spectral composition of light. Thus, PE does not account for plant response to differences in spectral quality of light emitted by a fixture. Several reports indicated a reduction in lettuce growth when spectral quality of supplied light is not optimized for a given light intensity (Johkan et al., 2010; Tosti et al., 2018; Zhang T. et al., 2018; Zhen and van Iersel, 2016). Moreover, effects of light spectrum on plant dry-matter production can be pronounced under low light intensities (Nelson and Bugbee, 2014), suggesting that spectrum of electric lighting can be an important determinant of EUE for indoor production. The disconnect between PE and SDW can be 
seen in recent reports on cucurbits (Hernandez and Kubota, 2014) and bedding plants (Park and Runkle, 2018). Thus, greater PE may lower EEC, but it is unclear whether it translates to greater EUE in indoor lettuce production when spectral quality of light is not optimized.

To better understand the effect of spectral quality of light on EUE and bridge the disconnect between PE and EUE in indoor lettuce farming, we conducted two experiments in which our objectives were to 1) study the effects of spectral quality of LEDs on lettuce SDW, EEC, and EUE; 2) verify whether greater PE can increase EUE for indoor lettuce production; and 3) assess other efficiency metrics associated with EUE for indoor lettuce production. The purpose of Expt. 1 was to study the aforementioned objectives using select lettuce varieties. The findings from Expt. 1 were then validated in Expt. 2 using a vertical hydroponic farm and three different lettuce varieties.

\section{Materials and Methods}

\section{Expt. 1}

Plant material and environmental conditions. Expt. 1 was conducted inside a greenhouse at Purdue University, West Lafayette, IN. To ensure that plants were grown under sole-source lighting only, two layers of weed cloth (WeedBlock; Jobes Co., Waco, TX) that allowed air movement but restricted sunlight transmission to less than $10 \mu \mathrm{mol} \cdot \mathrm{m}^{-2} \cdot \mathrm{s}^{-1}$ of intensity were used to cover the experimental setup. Seeds of green leaf lettuce (Lactuca sativa L. 'Black-Seeded Simpson') were germinated in 1.5 -inch $(3.8 \mathrm{~cm})$ rock wool starter plugs (Grodan, Stockton, CA). The starter plugs were put on a bench without weed cloth in the same greenhouse and transferred to a horizontal hydroponic production system (see the section "Growing system" to follow). Expt. 1 was conducted during the Winter of 2017 for 3 weeks. Temperature and relative humidity $(\mathrm{RH})$ were measured at the center of each replication using a Watchdog plant growth station (Model\# 2475; Spectrum Technologies, Aurora, IL). Average temperature and RH maintained were $25.6 \pm 1.37 / 18.3 \pm 1.15{ }^{\circ} \mathrm{C}$ (day/night) and $35.4 \pm 6.3 \%$, respectively, during germination and production.

Growing system. A custom production system was built using hydroponic trays $(1.22 \mathrm{~m} \times 0.61 \mathrm{~m} \times 0.1 \mathrm{~m}$, Active Aqua Co.; Hydrofarm, Petaluma, CA), LED lights (see the section "Light treatments"), nutrient solution reservoirs (20-gal; Active Aqua Co.; Hydrofarm), and submersible pumps (320 GPH or 20.2 LPM; TotalPond Co., West Palm Beach, FL). Reservoirs were connected to individual trays using flexible vinyl tubing (1.0-inch OD and 0.75 -inch ID, Everbilt Co.; Home Depot, Atlanta, GA). The area of each tray containing 32 plants was $0.74 \mathrm{~m}^{2}$. Plants were grown at a spacing of $0.15 \mathrm{~m} \times 0.15 \mathrm{~m}$. Trays were laid out horizontally with $0.61 \mathrm{~m}$ separation. The nutrient solution was recycled for $15 \mathrm{~min}$ at the beginning of every hour from 6:00 AM to 10:00 PM $(16 \mathrm{~h})$ each day by connecting the pump to a 24-h analog timer (Apollo 6; TitanControl, Villa Allende, Córdoba, Argentina) for automated operation. Fertilizer solution was prepared by combining $15-2.2-12.5$ and $21-2.2-16.6 \mathrm{~N}-\mathrm{P}-\mathrm{K}$ commercial mixes (The Scotts Co., Marysville, $\mathrm{OH})$ in a 3:1 ratio. Plants were supplied a nutrient solution with a concentration of 1.8 $\mathrm{dS} \cdot \mathrm{m}^{-1}\left(178 \mathrm{mg} \cdot \mathrm{L}^{-1} \mathrm{~N}\right)$ and $\mathrm{pH}$ of 5.8 and 6.2. $\mathrm{EC}$ and $\mathrm{pH}$ were measured using a digital probe (HI9811-0; Hanna Instruments, Smithfield, RI) twice every week to ensure that the values are within the targeted range. Recycled nutrient solution was discarded and reservoirs were refilled every week with fresh nutrient solution.

Light treatments. Plants were grown under four different light treatments using commercial LED lights including FRX (Fluence Razr X; Fluence Bioengineering, Austin, TX), FRP (Fluence Razr Physiospec Purple; Fluence Bioengineering), TGB (TG1A Bulbs; TotalGrow, Holland, MI), and LT8 (2GT8 432 A12 1/4; Lithonia Lighting, Conyers, GA). In the FRP fixture, a red diode with a peak emission at $659 \mathrm{~nm}$ is added to provide additional red light. There was one fixture in each light treatment. Fixtures were hung $0.4 \mathrm{~m}$ above the trays and spaced $0.3 \mathrm{~m}$ apart. Polystyrene sheets $(0.61 \mathrm{~m} \times 1.22 \mathrm{~m}$; U-line, Pleasant Prairie, WI) were placed along the length of each tray to contain dispersed light within each treatment but allow air from greenhouse cooling/heating. Plants were grown under a photoperiod of $16 \mathrm{~h}$ for each light treatment.

Measurements. Fixture cost $\left(\$ / \mathrm{m}^{2}\right)$ was calculated from manufacturer invoice receipts. Power consumption (W) by light fixtures was measured using Kill-a-Watt meter (P4400; P3 International, New York, $\mathrm{NY})$. The values were adjusted per $\mathrm{m}^{2}$ of lighted area $\left(\mathrm{P}, \mathrm{W} \cdot \mathrm{m}^{-2}\right)$ by dividing by 0.74 (each fixture covered an area of $0.74 \mathrm{~m}^{2}$ ). EEC $\left(\mathrm{KWh} \cdot \mathrm{m}^{-2}\right)$ was calculated as total energy consumed from start to end of the study:

$$
\begin{aligned}
E E C= & \int_{n=\text { start }}^{\text {end }} \mathrm{P}\left(\frac{\mathrm{W}}{\mathrm{m}^{2}}\right) \\
& \times 0.001\left(\frac{\mathrm{KW}}{\mathrm{W}}\right) \times 16\left(\frac{\mathrm{h}}{\mathrm{d}}\right)
\end{aligned}
$$

PE $\left(\mu \mathrm{mol} \cdot \mathrm{J}^{-1}\right)$ was obtained from the manufacturer label. For the LT8 fixture, lumens/s generated were obtained from the manufacturer specifications and converted to lumens $/ \mathrm{m}^{2} / \mathrm{s}$ by dividing by 0.74 . Lumens $/ \mathrm{m}^{2} / \mathrm{s}$ was converted to $\mu \mathrm{mol} \cdot \mathrm{m}^{-2}$ $\cdot \mathrm{s}^{-1}$ by multiplying by calibration factor (0.0135; Thimijan and Heins, 1982) for cool-white fluorescent lamps. PE for LT8 was calculated as the ratio of light intensity $\left(\mu \mathrm{mol} \cdot \mathrm{m}^{-2} \cdot \mathrm{s}^{-1}\right)$ produced to energy consumed $\left(\mathrm{W} \cdot \mathrm{m}^{-2}\right.$ or $\left.\mathrm{J} \cdot \mathrm{m}^{-2} \cdot \mathrm{s}^{-1}\right)$ by the fixture.

Incident photosynthetic photon flux density $\left(P P F D, \mu \mathrm{mol} \cdot \mathrm{m}^{-2} \cdot \mathrm{s}^{-1}\right)$ at canopy level below each light fixture was measured using a quantum sensor connected to a logger (LI190; LI-COR Biosciences, Lincoln, NE). A spectroradiometer (SS-110; Apogee Instruments, Logan, UT) with a hemispherical field-of-view $\left(180^{\circ}\right)$ was used to measure spectral quality of incident light. As both PPFD and spectral composition were measured during growth at canopy level (close to harvest stage), these measurements were likely affected by light reflected from plants in addition to incident light from the fixtures. From spectroradiometer measurements, total intensity between $400-700 \mathrm{~nm}\left(I_{\mathrm{PAR}}, \mu \mathrm{mol} \cdot \mathrm{m}^{-2} \cdot \mathrm{s}^{-1}\right)$, 400-499 $\mathrm{nm}$ (I $\left.I_{\text {blue }}, \mu \mathrm{mol} \cdot \mathrm{m}^{-2} \cdot \mathrm{s}^{-1}\right), 500$ $599 \mathrm{~nm}\left(I_{\text {green }}, \mu \mathrm{mol} \cdot \mathrm{m}^{-2} \cdot \mathrm{s}^{-1}\right)$, and 600 $700 \mathrm{~nm} \quad\left(I_{\text {red }}, \mu \mathrm{mol} \cdot \mathrm{m}^{-2} \cdot \mathrm{s}^{-1}\right)$ broadband wavelengths was calculated by adding intensities of individual wavelengths within each range. Percentage of blue, green, and red light output was calculated as following:

$$
\begin{gathered}
\text { Blue }=100 \times \frac{I_{\text {blue }}}{I_{\text {PAR }}}\left(\frac{\mu \mathrm{mol} \cdot \mathrm{m}^{-2} \cdot \mathrm{s}^{-1}}{\mu \mathrm{mol} \cdot \mathrm{m}^{-2} \cdot \mathrm{s}^{-1}}\right) \\
\text { Green }=100 \times \frac{I_{\text {green }}}{I_{\text {PAR }}}\left(\frac{\mu \mathrm{mol} \cdot \mathrm{m}^{-2} \cdot \mathrm{s}^{-1}}{\mu \mathrm{mol} \cdot \mathrm{m}^{-2} \cdot \mathrm{s}^{-1}}\right) \\
\text { Red }=100 \times \frac{I_{\text {red }}}{I_{P A R}}\left(\frac{\mu \mathrm{mol} \cdot \mathrm{m}^{-2} \cdot \mathrm{s}^{-1}}{\mu \mathrm{mol} \cdot \mathrm{m}^{-2} \cdot \mathrm{s}^{-1}}\right)
\end{gathered}
$$

In addition, the ratio of red to blue (R:B), red to green $(R: G)$, and blue to green $(B: G)$ was calculated.

$\mathrm{PE}_{\mathrm{R}}$ was calculated as following:

$$
P E_{R}=P E\left(\frac{\mu \mathrm{mol}}{J}\right) \times \frac{\mathrm{Red}}{100}
$$

Due to limited drying oven space, all (32) plants belonging to each treatment within each replication could not be dried at the same time. We harvested 12 plants from the center of each treatment within a replication and dried them at the same time. Shoots were dried in a forced-air oven set to $80{ }^{\circ} \mathrm{C}$ until the material was completely dry. SDW was determined by multiplying dry weight of 12 plants by 3.6 as there were 43 plants $/ \mathrm{m}^{2}$ in each treatment. From this, EUE (g.KWh ${ }^{-1}$ ) was calculated as:

$$
E U E=\frac{S D W}{E E C}\left(\frac{\mathrm{g} \cdot \mathrm{m}^{-2}}{\mathrm{KWh} \cdot \mathrm{m}^{-2}}\right)
$$

Experimental design and statistical analysis. The experiment used a randomized block design with four replications. Light treatments were randomized within each replication. An experimental unit was composed of 32 plants belonging to a light treatment within a replication. Data were analyzed using the analysis of variance procedure of statistical analysis software (SAS, version 9.4; SAS Institute, Cary, NC) and means were compared using the Tukey's honestly significant difference procedure. A model that included red, green, blue, R:B, R:G, B:G, and $P P F D$ as predictor 
Table 1. Fixture characteristics measured in Expt. 1.

\begin{tabular}{|c|c|c|c|c|c|c|c|c|c|c|c|}
\hline Fixture & Manufacturer/Model/Color & $\begin{array}{c}\text { Cost } \\
\left(\$ / \mathrm{m}^{2}\right)\end{array}$ & $\begin{array}{c}\text { Power } \\
\left(\mathrm{W} \cdot \mathrm{m}^{-2}\right)\end{array}$ & $\begin{array}{c}P P F D^{\mathrm{z}} \\
\left(\mu \mathrm{mol} \cdot \mathrm{m}^{-2} \cdot \mathrm{s}^{-1}\right)\end{array}$ & $\begin{array}{l}\text { Blue } \\
(\%)\end{array}$ & $\begin{array}{c}\text { Green } \\
(\%)\end{array}$ & $\begin{array}{l}\text { Red } \\
(\%)\end{array}$ & $\begin{array}{c}\mathrm{PE}^{\mathrm{y}} \\
\left(\mu \mathrm{mol} \cdot \mathrm{J}^{-1}\right)\end{array}$ & $\mathrm{R}: \mathrm{B}$ & $\begin{array}{c}\mathrm{PE}_{\mathrm{R}} \\
\left(\mu \mathrm{mol} \cdot \mathrm{J}^{-1}\right)\end{array}$ & $\begin{array}{c}\text { EUE } \\
\left(\mathrm{g} \cdot \mathrm{KWh}^{-1}\right)\end{array}$ \\
\hline$\overline{\mathrm{FRX}}$ & Fluence /RazrX/Warm-white & 456 & 120 & $217 a^{x}$ & $16.6 \mathrm{a}$ & $45.6 \mathrm{a}$ & $37.4 \mathrm{c}$ & 2.3 & $2.25 \mathrm{c}$ & $0.92 \mathrm{~b}$ & $1.03 \mathrm{~b}$ \\
\hline TGB & TotalGrow/TG1A/Dull purple & 471 & 138.6 & $140 \mathrm{~b}$ & $22.2 \mathrm{a}$ & $24.7 \mathrm{~b}$ & $52.6 \mathrm{~b}$ & 1.3 & $2.37 \mathrm{~b}$ & $0.65 \mathrm{c}$ & $0.66 \mathrm{~b}$ \\
\hline LT8 & Lithonia/2GT8/Cool-white & 207 & 95.8 & $137 \mathrm{~b}$ & $22.0 \mathrm{a}$ & $47.8 \mathrm{a}$ & $30.0 \mathrm{c}$ & 1.9 & $1.36 \mathrm{c}$ & $0.63 \mathrm{c}$ & $0.61 \mathrm{~b}$ \\
\hline FRP & Fluence/Razr/Purple & 569 & 174.5 & $232 \mathrm{a}$ & $14.9 \mathrm{a}$ & $21.6 \mathrm{~b}$ & $63.5 \mathrm{a}$ & 2.1 & $4.26 \mathrm{a}$ & $1.46 \mathrm{a}$ & $2.54 \mathrm{a}$ \\
\hline
\end{tabular}

${ }^{\mathrm{z}}$ Measured using a LI-COR quantum sensor.

${ }^{\mathrm{y}}$ Manufacturer provided values.

${ }^{\mathrm{x}}$ Means with different letters are significantly different at $P<0.05$.

$P P F D=$ photosynthetic photon flux density; blue = percentage of blue light; green = percentage of green light; red = percentage of red light; PE = photon efficiency; $\mathrm{R}: \mathrm{B}=$ ratio of percentage of red light to percentage of blue light; $\mathrm{PE}_{\mathrm{R}}=$ photon efficiency based on red light; EUE = electrical energy use efficiency.

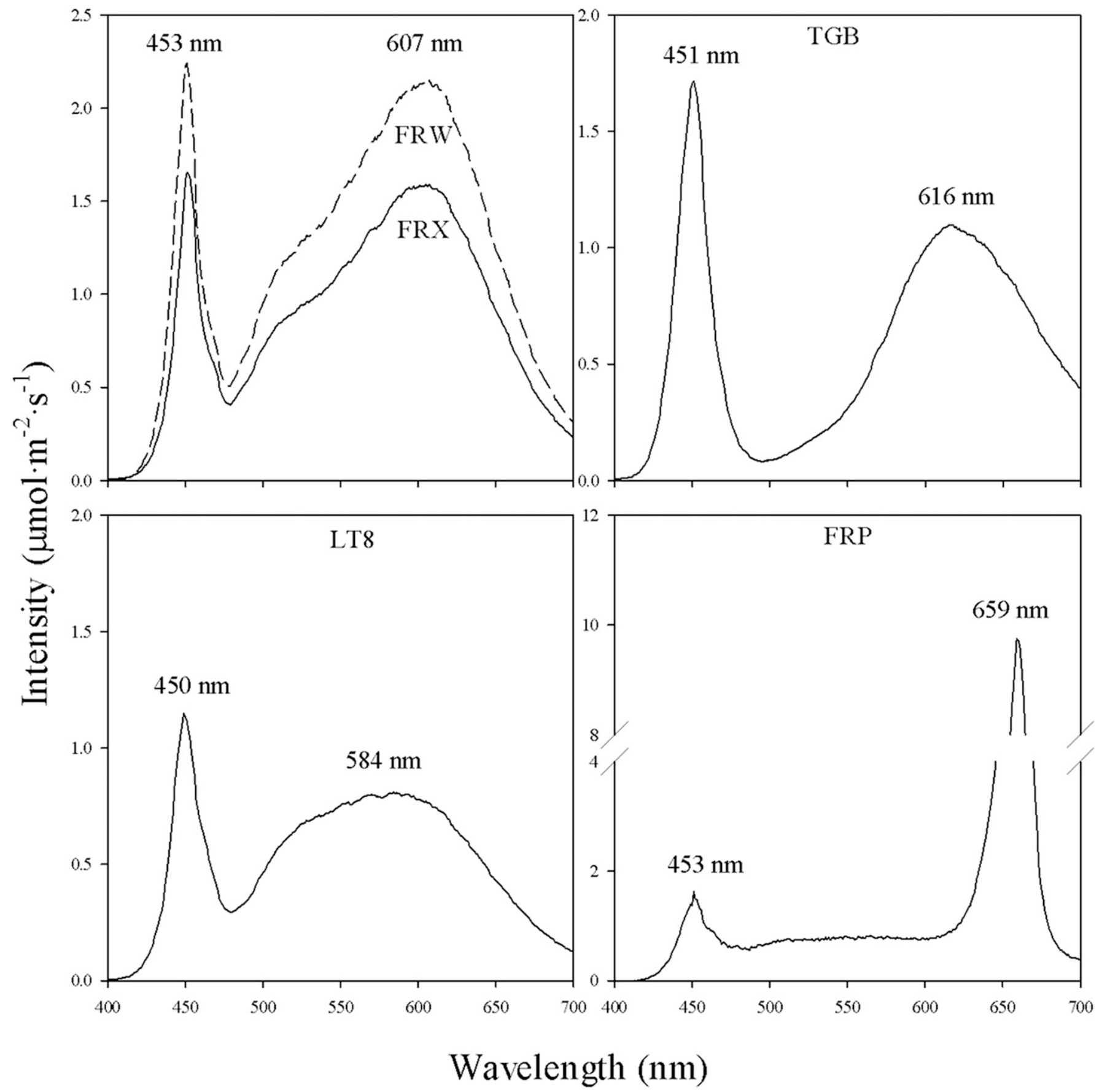

Fig. 1. Spectroradiometer measurement of light quality of pc-LED fixture treatments used in experiments. FRX: Fluence RazrX (Expt. 1), FRW: Fluence Razr Physiospec Warm White (Expt. 2), TGB: Total Grow bulb (Expt. 1), LT8: Lithonia T8 LED fluorescent lamp (Expt. 1), and FRP: Fluence Razr Physiospec Purple (Expts. 1 and 2). Peak wavelength numbers are shown for each fixture. Total light intensity between 400-499, 500-599, and 600-700 nm was added to determine broadband blue, green, and red-light intensities in the study. Pc-LED = phosphor conversion light-emitting diode. 


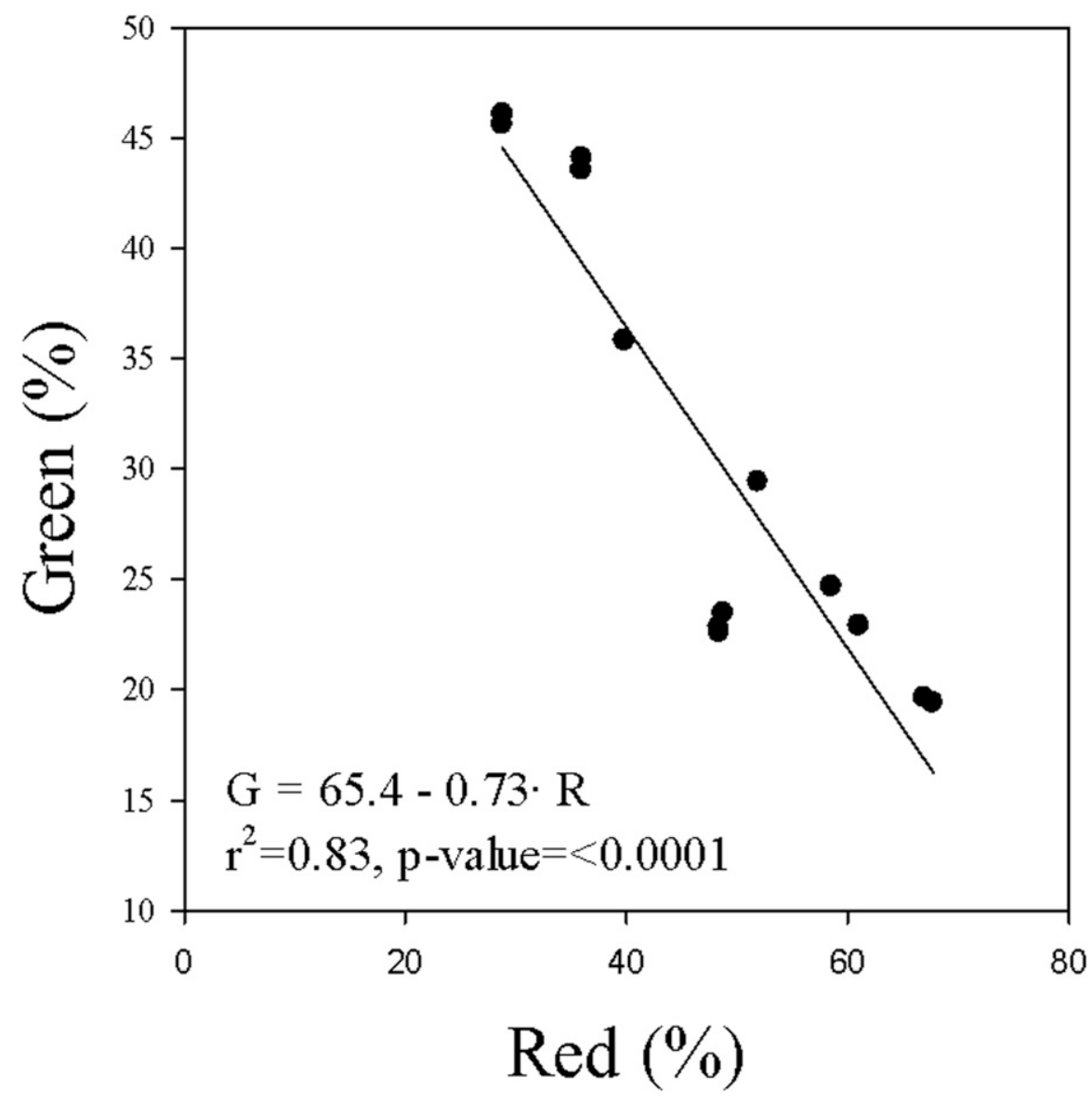

Fig. 2. Relationship between percentage of red and green light among LED fixtures in Expt. 1. A linear regression was fitted to describe the inverse relationship. A significant $P$ value indicates that slope of the fitted line is different from zero, and $r^{2}$ describes goodness of fit. Available data from all replications ( $\mathrm{n}=$ 4) and four light treatments were used in the regression analysis. LED = light-emitting diode.

Table 2. Results of stepwise model selection showing response variables, predictor variables, coefficient values for predictor variables, sE of estimate, $P$ value, partial $R^{2}$ for each variable, and model $R^{2}$.

\begin{tabular}{|c|c|c|c|c|c|c|}
\hline Response variable & Predictor variable & Estimate & SE & $P$ value & Partial $R^{2}$ & Model $R^{2}$ \\
\hline \multirow[t]{3}{*}{$\overline{\mathrm{EUE}}$} & Intercept & -1.6 & 0.86 & 0.09 & - & \multirow[t]{3}{*}{0.79} \\
\hline & $\mathrm{R}: \mathrm{B}$ & 1.9 & 0.68 & 0.01 & 0.69 & \\
\hline & $(\mathrm{R}: \mathrm{B})^{2}$ & -0.2 & 0.11 & 0.06 & 0.10 & \\
\hline \multirow[t]{3}{*}{ SDW } & Intercept & -208.1 & 67.14 & 0.012 & - & \multirow[t]{3}{*}{0.88} \\
\hline & $\mathrm{R}: \mathrm{B}$ & 204.1 & 52.87 & 0.003 & 0.78 & \\
\hline & $(\mathrm{R}: \mathrm{B})^{2}$ & -22.8 & 8.24 & 0.021 & 0.10 & \\
\hline \multirow[t]{2}{*}{ EEC } & Intercept & 25.6 & 10.73 & 0.03 & - & \multirow[t]{2}{*}{0.71} \\
\hline & $\mathrm{R}$ & 1.1 & 0.22 & 0.0006 & 0.71 & \\
\hline
\end{tabular}

${ }^{\mathrm{z}}$ The following multivariate model was fitted to the data: $Y=\beta_{0} \pm \beta_{1} \times B \pm \beta_{2} \times G \pm \beta_{3} \times R \pm \beta_{4} \times P P F D \pm \beta_{5} \times$ $R: B \pm \beta_{6} \times(R: B)^{2} \pm \beta_{7} \times R: G \pm \beta_{8} \times(R: G)^{2} \pm \beta_{9} \times B: G \pm \beta_{10} \times(B: G)^{2}$, where $Y$ is response variable, $R, B$, and $G$ represent percentage of red, blue, and green light, respectively, and PPFD is incident light intensity.

$\mathrm{EUE}=$ electrical energy-use efficiency; SDW $=$ shoot dry weight per $\mathrm{m}^{2} ; \mathrm{EEC}=$ total electrical energy consumption per $\mathrm{m}^{2}$.

variables was used to describe response variables including SDW, EEC, and EUE. Stepwise selection procedure $(P$ value for variable entry $=0.1$ and $P$ value for variable stay $=0.05)$ was used to fit the model using SAS. Linear and quadratic regressions were fitted to the univariate data using regression procedure of SAS. A predetermined alpha value of $5 \%(P \leq 0.05)$ was considered statistically significant for all analyses.

\section{Expt. 2}

Plant material and environmental conditions. Expt. 2 was conducted inside the same greenhouse as Expt. 1 at Purdue University, West Lafayette, IN. A weed cloth (WeedBlock) was used to achieve the same purpose as Expt. 1 to cover the experimental setup. Three lettuce varieties belonging to leaf (var. Redina), butter head (var. Rex), and romaine (var. Organic Rouge d'Hiver) groups were germinated as in Expt. 1 and transferred to an indoor vertical farm (see the section "Growing system" to follow). Expt. 2 was conducted during the summer of 2018 for $23 \mathrm{~d}$. Average temperature and $\mathrm{RH}$ were maintained at $26.3 \pm 1.15 / 20.5 \pm 0.56{ }^{\circ} \mathrm{C}$ (day/night) and $\mathrm{RH}$ at $65.7 \pm 6.97 \%$ during the experiment.
Growing system. A custom vertical farm was built using same hydroponic trays, pumps, and reservoirs as in Expt. 1, wired shelving units $(1.21 \mathrm{~m} \times 0.61 \mathrm{~m} \times 1.98 \mathrm{~m}$, Huskey Model \#MR482478WS; Home Depot), and LED lights (see the section "Light treatments"). The trays were spaced $0.5 \mathrm{~m}$ apart vertically within each shelf. Nutrient solution was continuously recycled (closedloop) during the experiment among the trays and reservoir in each shelf. The fertilizer type, nutrient-solution concentration, $\mathrm{pH}$, and plant spacing were similar to those used in Expt. 1. Three lettuce varieties, with 10 plants per variety and two gap fillers, were grown in each tray.

Light treatments. Plants were grown under two different commercial LED fixtures, i.e., FRW (Fluence Razr PhysioSpec White; Fluence Bioengineering) and FRP (Fluence Razr Physiospec Purple; Fluence Bioengineering). The FRW fixture was similar to the FRX fixture used in Expt. 1, except that an additional array of LED lights was present in FRW to increase the electrical power requirement and $P P F D$ to equivalent levels of the FRP fixture (Table 3 ). Fixtures were hung $0.4 \mathrm{~m}$ above trays with one fixture belonging to one tray. Light treatments were isolated from each other using black plastic sheets. Plants were grown under a 24-h photoperiod in each light treatment. Continuous lighting was used to maximize EUE in each light treatment.

Measurements. Similar to Expt. 1, fixture cost $\left(\$ / \mathrm{m}^{2}\right)$, power consumption $\left(\mathrm{W} \cdot \mathrm{m}^{-2}\right)$, EEC $\left(\mathrm{KWh} \cdot \mathrm{m}^{-2} \cdot \mathrm{d}^{-1}\right)$, PPFD $\left(\mu \mathrm{mol} \cdot \mathrm{m}^{-2} \cdot \mathrm{s}^{-1}\right)$, blue $(\%)$, green $(\%)$, red $(\%), \mathrm{R}: \mathrm{B}$, and $\mathrm{PE}_{\mathrm{R}}$ $\left(\mu \mathrm{mol} \cdot \mathrm{J}^{-1}\right)$ were measured. Four plants from the center of production area and belonging to each of the three varieties were harvested after $23 \mathrm{~d}$ of growth. Shoots were dried in a forced-air oven set to $80{ }^{\circ} \mathrm{C}$ until the material was completely dry. SDW was determined by multiplying dry weight of 4 plants by 10.75 as there were 43 plants $/ \mathrm{m}^{2}$ in each treatment. From this, EUE $\left(\mathrm{g} \cdot \mathrm{KWh}^{-1}\right)$ was calculated as described in Expt. 1.

Experimental design and statistical analysis. The experiment used a split-plot design with four replications. A replication contained three shelves, each treated as a subsample. Each shelf contained two light treatments (main level). In each light treatment, there were three varieties (split level) with 10 plants grouped together. Both main and split-levels were randomized within each shelf and replication. An experimental unit was composed of 10 plants belonging to a variety under a light treatment within a shelf. Data from three subsamples were collected separately and averaged before the analyses. For analyzing EUE and SDW, a split-plot model was used with an appropriate "error term" for main and split levels. As $P P F D$, blue, green, red, and $P E_{\mathrm{R}}$ were the same for a fixture (or all three varieties in a tray), they were analyzed using a randomized complete block model. Mean comparisons were made using the Tukey's 


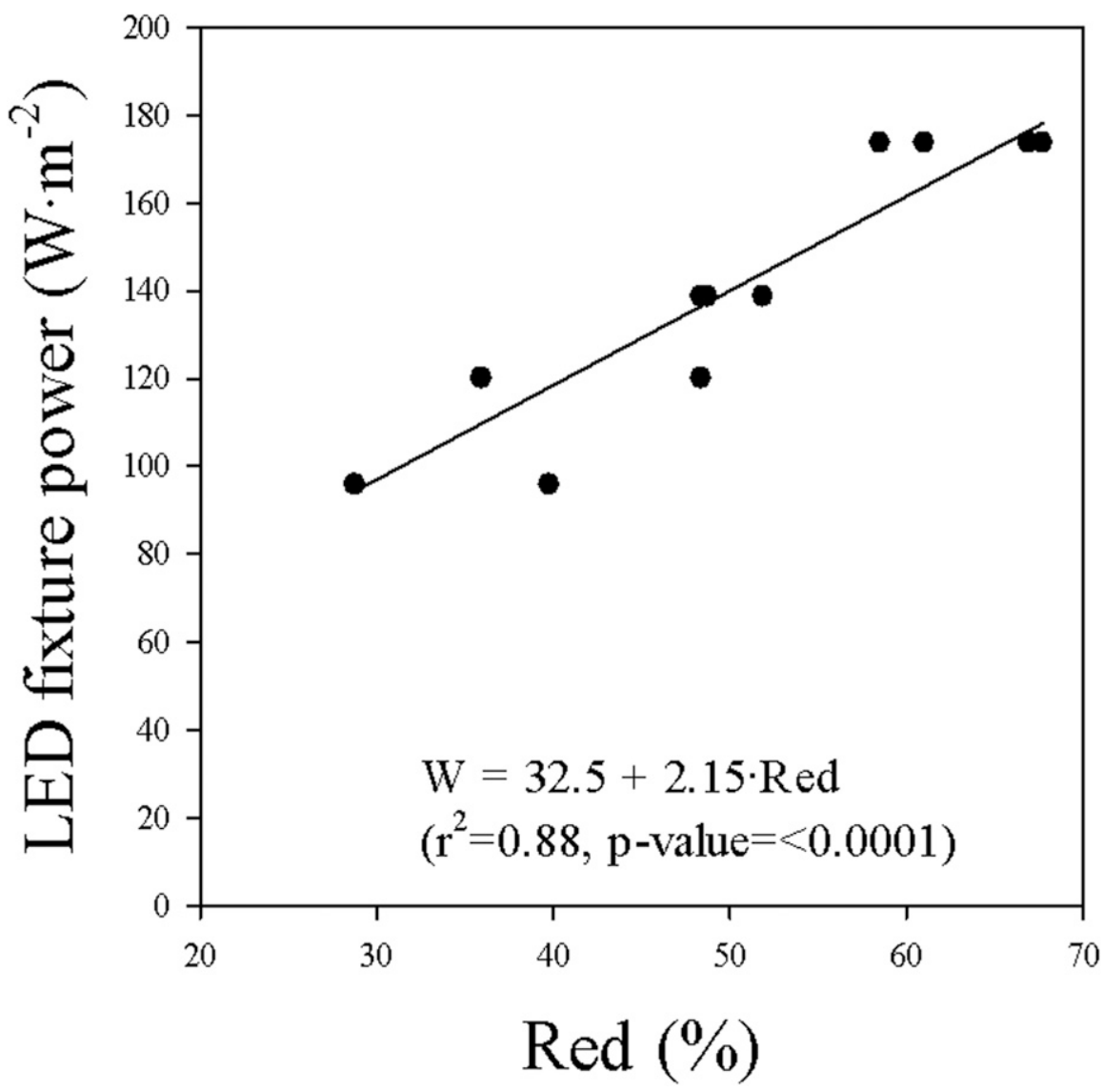

Fig. 3. Effect of increasing percentage of red light in the incident light on LED fixture power requirement (W) in Expt. 1. Linear regression was fitted to describe the relationships. A significant $P$ value indicates that slope of the fitted line is different from zero, and $r^{2}$ describes goodness of fit. Available data from all replications $(n=4)$ and four light treatments were used in the regression analysis. LED $=$ lightemitting diode.

honestly significant difference procedure (SAS, version 9.4; SAS Institute) with a predetermined alpha value of $5 \%(P \leq 0.05)$ was considered statistically significant in the analyses.

\section{Results and Discussion}

LED fixture characteristics in Expt. 1. In Expt. 1, our goal was to expose plants to a range of red, blue, and green percentages and $P P F D$ levels using LED fixtures that differed in electrical power requirement for modeling purposes. Fixture cost $/ \mathrm{m}^{2}$ ranged from US $\$ 207$ to 569. PPFD was significantly different among LED fixtures, with FRX and FRP greater than LT8 and TGB (Table 1). PPFD levels ranged from 137 to $232 \mu \mathrm{mol} \cdot \mathrm{m}^{-2} \cdot \mathrm{s}^{-1}$ (Table 1 ). Spectral quality of light was significantly different among LED fixtures. Percentage of blue, green, and red light ranged from 14.2 to $22.2,21.6$ to 47.8 , and 30.0 to 63.5 , respectively, among fixtures. The greatest percentage of red and green light was produced by FRP and FRX, respectively (Table 1, Fig. 1). Although numerically different, there were no statistical differences in percentage of blue light among LED fixtures (Table 1). Fixture power requirements ranged from 95.8 to ferent among fixtures (Table 1), it was not a significant predictor variable in the fitted models (Table 2). In the low range of PPFD levels to which plants were exposed, spectral quality of light likely can have a pronounced effect on observed plant responses (Nelson and Bugbee, 2014). Fitted model indicated that EEC was linearly related to percentage of red-light output by fixtures (Table 2). On the basis of the fitted model, a greater percentage of red-light output will increase fixture energy consumption and lower EUE as EEC and EUE are inversely related. However, the modeling approach indicated that linear and quadratic terms for R:B [i.e., $R: B$ and $\left.\left(R: B^{2}\right)\right]$ were significant predictor variables for SDW and EUE (Table 2). This indicates that EUE increased in a curvilinear fashion with increasing R:B (i.e., with percentage of red). As EUE is a ratio of SDW and EEC, it is possible that SDW has larger effect than EEC on EUE, which likely increased EUE initially with a greater percentage of red-light output of the incident light. However, EUE increased in a curvilinear fashion at greater levels of red-light output due to a relatively larger effect of greater EEC than SDW on EUE. Interestingly, the percentage of green light was not a significant predictor in the model. This may be because of the inverse relationship between percentages of red and green light among LED fixtures (Fig. 2), and the variability in EUE due to green light was likely accounted for by red light. These results indicate that spectral quality of light, especially red light, can have a larger impact on EUE (within the range of $P P F D$ levels used in our study).

A linear relationship was observed between LED fixture power requirement (proportional to EEC) and percentage of red-light output by the fixture (Fig. 3). Fixture power increased by $2.15 \mathrm{~W} \cdot \mathrm{m}^{-2}$ for a percent increase in red-light output, among LED lights. This is likely because of large "down conversion" associated with red light emission and associated heat generation in the phosphor layer (Huang and Yang, 2013). This likely increased the temperature of phosphor material. Increase in temperature lowers "luminous efficacy" (photons produced per unit EEC) of phosphor emission (Ryu and Ryu, 2015). Thus, more electrical energy was likely needed to produce a greater percentage of red light from LED lights used in our study.

The curvilinear relationships between SDW or EUE and R:B (Fig. 4, top and middle) indicate that SDW and EUE increased initially with increasing R:B up to a maximum, followed by a decrease with further increases in R:B. Maximum EUE was observed when R:B was 4.47 (calculated by equating the slope of the fitted quadratic equation to zero; Fig. 4, middle). Previously, an R:B value of 4.0 resulted in greater biomass and better quality of lettuce in other studies (Kim et al., 2004; Mickens et al., 2018; Zhang T. et al., 2018). A similar $\mathrm{R}: \mathrm{B}$ increased the photosynthetic saturation 

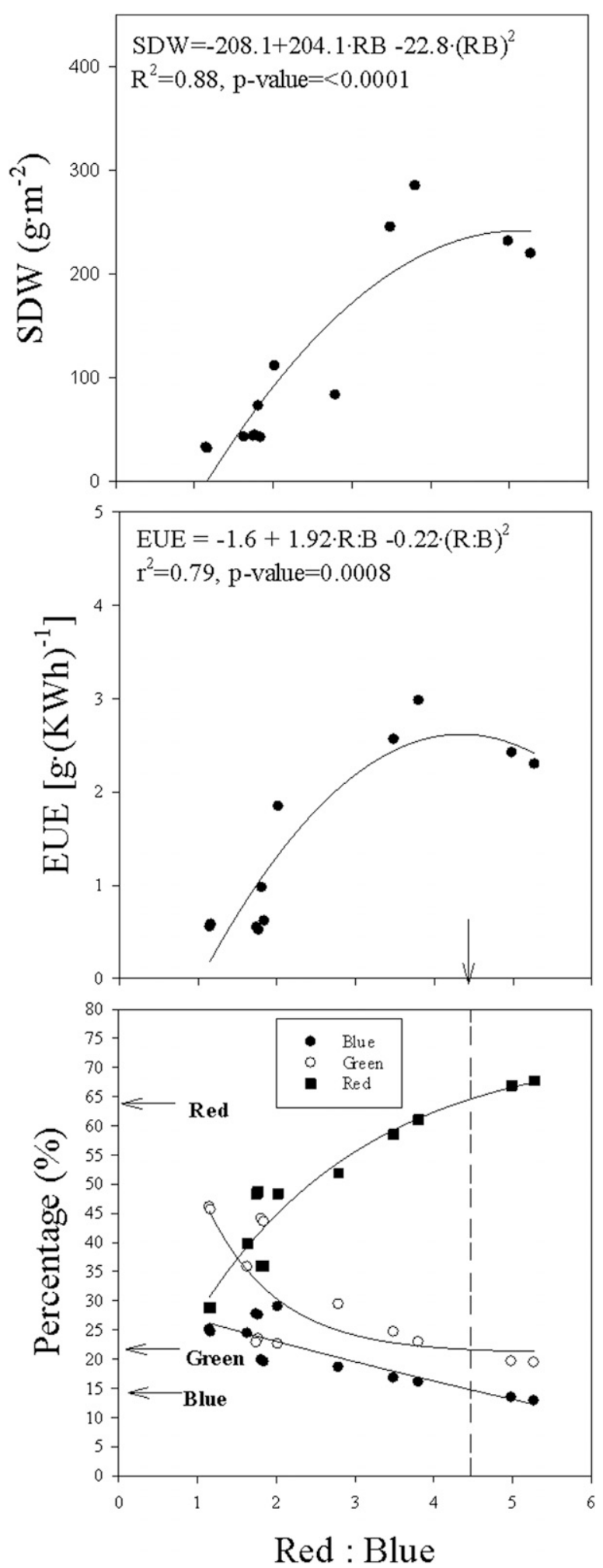

Fig. 4. Top, relationship between shoot dry weight per $\mathrm{m}^{2}$ (SDW) and red-to-blue ratio (red: blue) among LED fixtures in Expt. 1. A quadratic equation of the form $y=a \pm b x \pm c x^{2}$ was fitted to describe the relationship. Middle, relationship between EUE and red:blue among LED fixtures in Expt. 1. A quadratic equation of the form $y=a \pm b x \pm c x^{2}$ was fitted to describe the relationship. Arrow points to a red:blue of 4.47 where EUE was maximum (calculated at the point on $x$-axis when slope of the fitted quadratic equation is zero) among the fixtures. Bottom, relationship between percentage of red, green, and blue light and red:blue among LED fixtures in Expt. 1. Exponential equation of the form $y=a\left(1-e^{-b x}\right)$ was fitted to describe the relationship between red vs. red:blue whereas an exponential equation of the form $y=a e^{-b x}$ was fitted to describe the relationship between green or blue vs. red:blue. The dashed vertical line intersects the fitted curves at red:blue value of 4.47. From this percentage of red, green, and blue light that can result in maximum EUE are shown by arrows along y-axis. LED = light-emitting diode; EUE = electrical energy-use efficiency. point and nitrogen accumulation in leaves of rice (Matsuda et al., 2004), whereas spinach preferred a greater proportion of blue light than lettuce (Yorio et al., 2001).

Initial increase in SDW, and thereby EUE, with increasing R:B was likely due to a positive effect of greater percentage of red on lettuce growth. Leaf expansion and shoot growth of lettuce were shown to be greater under red light in other studies (Kang et al., 2016; Lee and Kim, 2013; Poulet et al., 2014; Wang et al., 2016; Wojciechowska et al., 2015; Zhang T. et al., 2018). In addition, a negative effect of a greater fraction of blue light on leaf and shoot growth in lettuce was also previously reported (Hoenecke et al., 1992; Tosti et al., 2018). Lower leaf growth in lettuce at a greater percentage of blue light is likely a photomorphogenic response to minimize the interception of high-energy blue photons, which may damage the photosystem complex (Loreto et al., 2009). In contrast, the observed decrease in EUE at greater R:B is likely due to a larger increase in EEC at greater R:B.

Using the relationships between red, green, and blue output among fixtures and $\mathrm{R}: \mathrm{B}$, the optimal spectral quality of LEDs that results in maximum EUE (when R:B was 4.47 ) was estimated as $65 \%$ red, $25 \%$ green, and $15 \%$ blue light in the incident light (Fig. 4, bottom). In support, Kim et al. (2004) reported that red, green, and blue percentages of 61,24 , and 15 , respectively, resulted in the greatest lettuce biomass production, which agrees with our findings. These results indicate that red light quality is an important determinant of EEC and EUE.

Relationship between PE and EUE. Manufacturer-provided PE values ranged from 1.3 to $2.3 \mu \mathrm{mol} \cdot \mathrm{J}^{-1}$ among LED fixtures (Table 1). Both Fluence fixtures had greater values $\left(2.3\right.$ and $\left.2.1 \mu \mathrm{mol} \cdot \mathrm{J}^{-1}\right)$ followed by LT8 (1.9 $\left.\mu \mathrm{mol} \cdot \mathrm{J}^{-1}\right)$ and the TGB fixture $\left(1.3 \mu \mathrm{mol} \cdot \mathrm{J}^{-1}\right)$. Although PE was similar between FRX and FRP, large differences in EUE were observed between them (1.03 vs. $2.54 \mathrm{~g} \cdot \mathrm{KWh}^{-1}$, Table 1). Moreover, large differences in PE between TGB and LT8 (1.3 vs. $\left.1.9 \mu \mathrm{mol} \cdot \mathrm{J}^{-1}\right)$ did not result in any differences in EUE between them (Table 1). These results suggest that $\mathrm{PE}$ is likely not a good predictor of EUE in lettuce production. It is important to note that our results are specific to lettuce and differ from previous research that generally suggested using PE for LEDfixture selection for many species (Both et al., 2017; Nelson and Bugbee, 2014; Park and Runkle, 2018). In contrast to PE, a strong relation was observed between EUE and $\mathrm{PE}_{R}$ (Fig. 5). This is because EUE increased curvilinear fashion with R:B (Table 2) and $\mathrm{PE}_{\mathrm{R}}$ accounts for red-light quality in the incident light.

Lettuce productivity and EUE in Expt. 2. Our goal for Expt. 2 was to keep fixture cost, power requirement, $P P F D$, and $\mathrm{PE}$ similar but vary red, $R: B$, and $P E_{R}$ between fixtures to validate the observed effects of spectral composition of light on EUE. Fixture cost 


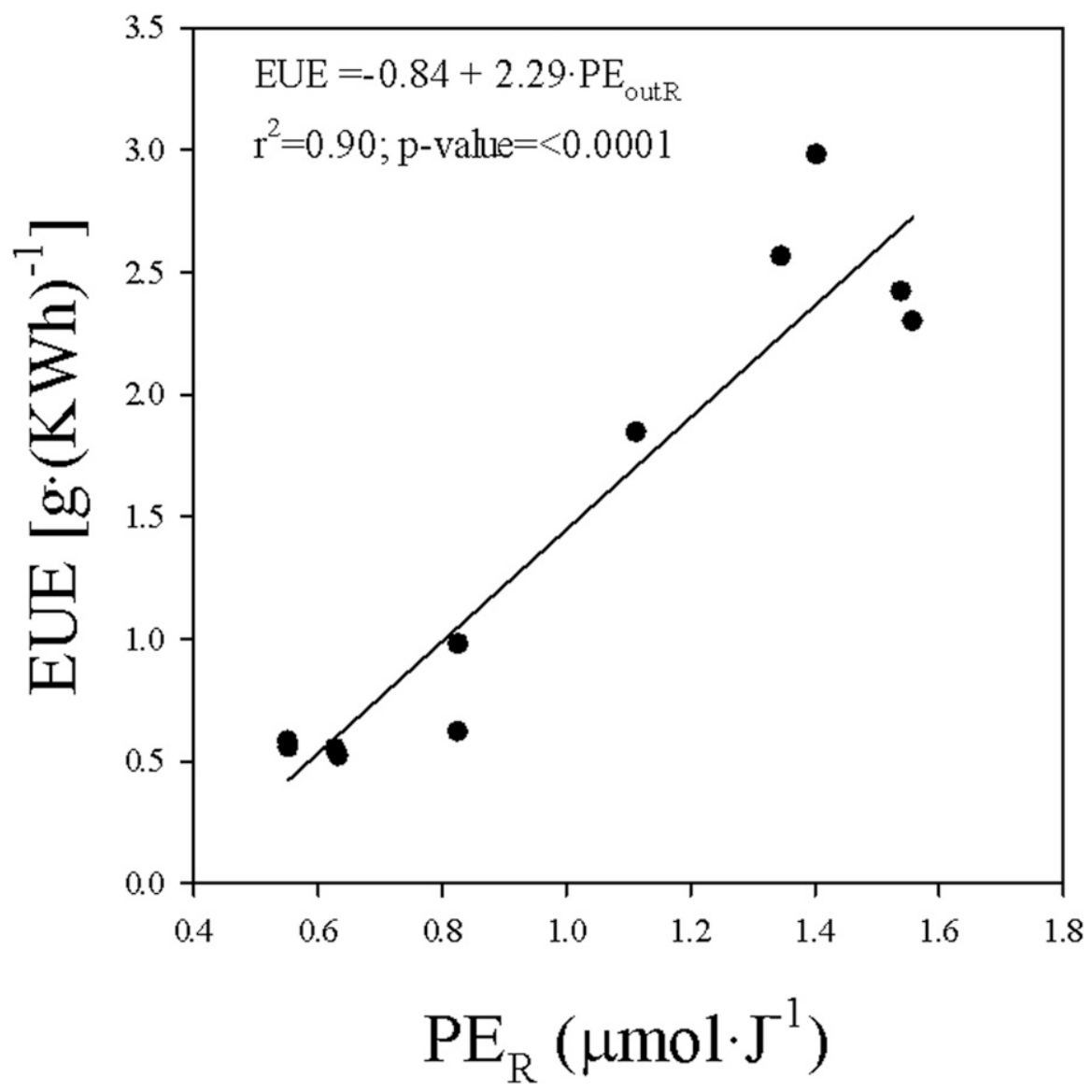

Fig. 5. Relationship between EUE and $\mathrm{PE}_{\mathrm{R}}$ in Expt. 1. Linear regression was fitted to describe the relationship. A significant $P$ value indicates that slope of the fitted line is different from zero, and $r^{2}$ describes goodness of fit. Available data from all replications $(n=4)$ and four light treatments were used in the regression analysis. $\mathrm{EUE}=$ electrical energy-use efficiency; $\mathrm{PE}_{\mathrm{R}}=$ photon efficiency based on red light.

and electric power requirement were similar between the two fixtures used in Expt. 2 (Table 3). There were no statistical differences in $P P F D$ between the two fixtures (Table 3). Manufacturer-provided PE values were similar for both fixtures $(2.3$ and $2.1 \mu \mathrm{mol} \cdot \mathrm{J}^{-1}$ for FRW and FRP, respectively). However, there were significant differences in spectral quality of light between the two fixtures. Percentages of blue and green were greater in FRW than for FRP, whereas percentage of red was greater in FRP compared with FRW (Table 3). Spectral composition of FRW was similar to FRX fixture (Expt. 1) with a peak red emission at $607 \mathrm{~nm}$, whereas FRP fixture has a peak emission at $659 \mathrm{~nm}$. Importantly, FRP had significantly greater $\mathrm{PE}_{\mathrm{R}}$ compared with FRW (1.46 vs. 0.81 $\left.\mu \mathrm{mol} \cdot \mathrm{J}^{-1}\right)$ due to a significantly greater percentage of red light from FRP than from the FRW fixture (Table 3). This resulted in a significantly greater R:B in FRP (4.3) vs. FRW (1.7).

Statistical analysis indicated a significant effect of LED fixture on EUE. Averaged across three varieties, EUE was significantly greater under FRP than FRW by $24.5 \%$ (Table 3 ). The effect of fixture on SDW was not statistically different
$(P=0.07)$. However, averaged across three varieties, it was greater by $20.7 \%$ for FRP than for FRW (Table 3). The observed differences in SDW and EUE are associated with differences in light spectral composition between the two fixtures. A lower percentage of blue and green light and higher percentage of red light likely resulted in better shoot growth, thereby greater EUE of lettuce varieties under FRP compared with FRW. Red light wavelength of $660 \mathrm{~nm}$ was found to be photosynthetically more efficient than that at $600 \mathrm{~nm}$ (McCree, 1971) and also could have contributed to increased SDW and EUE of FRP than FRW fixture. These results support that $\mathrm{PE}_{\mathrm{R}}$ can be more useful than $\mathrm{PE}$ for lettuce production, and fixture selection based on $\mathrm{PE}_{\mathrm{R}}$ can increase lettuce productivity and maximize EUE in indoor lettuce farming.

In conclusion, our results indicate that light spectral quality can have a large impact on EUE for lettuce production. Greater percentage of red increased $\mathrm{R}: \mathrm{B}$, which further increased EUE in a curvilinear fashion. Although a greater percentage of red directly increased EEC, effects of red light or $\mathrm{R}: \mathrm{B}$ on $\mathrm{SDW}$ were more dominant and increased EUE. A poor correlation was 
observed between EUE and PE in lettuce production, mainly because EUE in lettuce production is strongly influenced by spectral quality of light. We found a good relationship between EUE and $\mathrm{PE}_{\mathrm{R}}$, an efficiency metric that accounts for spectral quality of red light among fixtures. A suggestion is made here for lettuce growers to consider LED fixtures with high $\mathrm{PE}_{\mathrm{R}}$ and $\mathrm{R}: \mathrm{B}$ of $\approx 4.0$ to 4.5 in indoor lettuce farming.

\section{Literature Cited}

Agrilyst. State of indoor farming. 2017. 8 Jan. 2018. $<$ https://www.agrilyst.com/stateofindoorfarming $2017>$.

Barbosa, G., F. Gadelha, N. Kublik, A. Proctor, L. Reichelm, E. Weissinger, G. Wohlleb, and R. Halden. 2015. Comparison of land, water, and energy requirements of lettuce grown using hydroponic vs. conventional agricultural methods. Intl. J. Environ. Res. Public Health. 12:6879-6891.

Both, A.J., B. Bugbee, C. Kubota, R.G. Lopez, C. Mitchell, E.S. Runkle, and C. Wallace. 2017. Proposed product label for electric lamps used in the plant sciences. HortTechnology 27:544-549.

Bourget, C.M. 2008. An introduction to lightemitting diodes. HortScience 43:1944-1946.

Hernandez, R. and C. Kubota. 2014. Growth and morphological response of cucumber seedlings to supplemental red and blue photon flux ratios under varied solar daily light integrals. Scientia Hort. 27:92-99.

Hoenecke, M.E., R.J. Bula, and T.W. Tibbitts. 1992. Importance of 'blue' photon levels for lettuce seedlings grown under red-lightemitting diodes. HortScience 27:427-430.

Huang, M. and L. Yang. 2013. Heat generation by the phosphor layer of high-power white LED emitters. IEEE Photonics Technol. Lett. 25:1317-1320.

Johkan, M., K. Shoji, F. Goto, S. Hashida, and T. Yoshihara. 2010. Blue light-emitting diode light irradiation of seedlings improves seedling quality and growth after transplanting in red leaf lettuce. HortScience 45:1809-1814.

Kang, W.H., J.S. Park, K.S. Park, and J.E. Son. 2016. Leaf photosynthetic rate, growth, and morphology of lettuce under different fractions of red, blue, and green light from light-emitting diodes (LEDs). Hort. Environ. Biotechnol. 57:573-579.

Kim, H., G.D. Goins, R.M. Wheeler, and J.C. Sager. 2004. Green-light supplementation for enhanced lettuce growth under red- and blue-lightemitting diodes. HortScience 39:1617-1622.
Kozai, T. 2013. Resource use efficiency of closed plant production system with artificial light: Concept, estimation and application to plant factory. Proc. Jpn. Acad., Ser. B Phys. Biol. Sci. 89:447-461.

Kubota, C., M. Kroggel, A.J. Both, J.F. Burr, and M. Whalen. 2016. Does supplemental lighting make sense for my crop? -empirical evaluations. Acta Hort. (1134):403-411.

Lee, H.I. and Y.H. Kim. 2013. Utilization efficiencies of electric energy and photosynthetically active radiation of lettuce grown under red LED, glue LED and fluorescent lamps with different photoperiods. J. Biosys. Eng. 38:279-286.

Loreto, F., T. Tsonevand, and M. Centritto. 2009. The impact of blue light on leaf mesophyll conductance. J. Expt. Bot. 60:2283-2290.

Matsuda, R., K. Ohashi-Kaneko, K. Fujiwara, E. Goto, and K. Kurata. 2004. Photosynthetic characteristics of rice leaves grown under red light with or without supplemental blue light. Plant Cell Physiol. 45:1870-1874.

McCree, K.J. 1971. Action spectrum, absorptance and quantum yield of photosynthesis in crop plants. Agric. Met. 9:191-216.

Mickens, M.A., E.J. Skoog, L.E. Reese, P.L. Barnwell, L.E. Spencer, G.D. Massa, and R.M. Wheeler. 2018. A strategic approach for investigating light recipes for 'Outredgeous' red romaine lettuce using white and monochromatic LEDs. Life Sci. Space Rese. 19:5362.

Nelson, J.A. and B. Bugbee. 2014. Economic analysis of greenhouse lighting: Light emitting diodes vs. high intensity discharge fixtures. PLoS One 9(6):E99010.

Park, Y. and E.S. Runkle. 2018. Spectral effects of light-emitting diodes on plant growth, visual color quality, and photosynthetic photon efficacy: White versus blue plus red radiation. PLoS One 13(8):E0202386, doi: https://doi.org/ 10.1371/journal.pone.0202386.

Pattison, P.M., J.Y. Tsao, G.C. Brainard, and B. Bugbee. 2018. LEDs for photons, physiology and food. Nature 563:493-500.

Poulet, L., G.D. Massa, R.C. Morrow, C.M. Bourget, R.M. Wheeler, and C.A. Mitchell. 2014. Significant reduction in energy for plant growth lighting in space using targeting lighting and spectral manipulation. Life Sci. Space Rese. 2:43-53.

Pust, P., P.J. Schmidt, and W. Schnick. 2015. A revolution in lighting. Nat. Mater. 14:454-458.

Rabara, R.C., G. Behrman, T. Timbol, and P.J. Rushton. 2017. Effect of spectral quality of monochromatic LED light on the growth of artichoke seedlings. Front Plant Sci. 8:190 eCollection 2017.
Ryu, G.-H. and H.-Y. Ryu. 2015. Analysis of the temperature dependence of phosphor conversion efficiency in white light-emitting diodes. J. Opt. Soc. Korea 19:311-316.

Shimizu, H., Y. Saito, H. Nakashima, J. Miyasaka, and K. Ohdoi. 2011. Light Environment Optimization for Lettuce Growth in Plant Factory. IFAC Proc. Vol. 44:605-609.

Thimijan, R.W. and R.D. Heins. 1982. Photometric, radiometric, and quantum light units of measure: A review of procedures for interconversion. HortScience 18:818-822.

Tosti, G., P. Benincasa, R. Cortona, B. Falcinelli, M. Farneselli, M. Guiducci, A. Onofri, E. Pannacci, F. Tei, and M. Giulietti. 2018. Growing lettuce under multispectral light-emitting diodes lamps with adjustable light intensity. Ital. J. Agron. 13:57-62.

Voss, J. 2011. Market special: Greenhouse farming in Germany. The Ministry of Economics Affairs, Agriculture and Innovation, NL, EVD International. 7 May 2011. http://duitsland. nlambassade.org/binaries/content/assets/posten$\mathrm{web} / \mathrm{d} /$ duitsland/ambassadeberlijn/zaken-doen/ 20110507-marktverkenning-greenhouse-farminggermany.pdf.

Wang, J., W. Lu, Y. Tong, and Q. Yang. 2016. Leaf morphology, photosynthetic performance, chlorophyll fluorescence, stomatal development of lettuce (Lactuca sativa 1.) exposed to different ratios of red light to blue light. Front. Plant Sci. 7:250.

Wojciechowska, R., O. Długosz-Grochowska, A. Kołton, and M. Żupnik. 2015. Effects of LED supplemental lighting on yield and some quality parameters of lamb's lettuce grown in two winter cycles. Scientia Hort. 187:80-86.

Yam, F.K. and Z. Hassan. 2005. Innovative advances in LED technology. Microelectronics J. 36:129-137.

Yorio, N.C., G.D. Goins, and H.R. Kagie. 2001 Improving Spinach, Radish, and Lettuce Growth under Red Light-emitting Diodes (LEDs) with Blue Light Supplementation. HortScience 36:380-383.

Zhang, T., Y. Shi, F. Piao, and Z. Sun. 2018. Effects of different LED sources on the growth and nitrogen metabolism of lettuce. Plant Cell Tissue Organ Cult. 134:231-240.

Zhang, X., D.X. He, G.H. Niu, Z.N. Yan, and J.X. Song. 2018. Effects of environment lighting on the growth, photosynthesis, and quality of hydroponic lettuce in a plant factory. Intl. J. Agr. Biol. Eng. 11:33-40.

Zhen, S and M.W. van Iersel. 2016. Far-red light is needed for efficient photochemistry and photosynthesis. J. Plant Physiol. 209:115-122. 